https://helda.helsinki.fi

The effect of vitamin $C$ on upper respiratory infections in adolescent swimmers: A randomized trial

Constantini, N. W.

2011

Constantini , N W , Dubnov-Raz , G, Eyal , BB , Berry , EM , Cohen , AH \& Hemilä , H 2011

, ' The effect of vitamin $C$ on upper respiratory infections in adolescent swimmers: A

randomized trial ' , European journal of pediatrics , vol. 170 , no. 1 , pp. 59-63 . https://doi.org/10.1007/s00431-010-1

http://hdl.handle.net/10138/228085

https://doi.org/10.1007/s00431-010-1270-z

acceptedVersion

Downloaded from Helda, University of Helsinki institutional repository.

This is an electronic reprint of the original article.

This reprint may differ from the original in pagination and typographic detail.

Please cite the original version. 


\title{
The effect of vitamin $C$ on upper respiratory infections in adolescent swimmers: a randomized trial
}

Naama W. Constantini, Gal Dubnov-Raz, Ben-Bassat Eyal, Elliot M. Berry, Avner H. Cohen, Harri Hemilä

\author{
Harri Hemilä \\ Department of Public Health, \\ University of Helsinki, Finland \\ harri.hemila@helsinki.fi \\ http://www.mv.helsinki.fi/home/hemila
}

\section{This is a manuscript version of:}

Constantini NW, Dubnov-Raz G, Eyal BB, Berry EM, Cohen AH, Hemilä H.

The effect of vitamin $\mathrm{C}$ on upper respiratory infections in adolescent swimmers: a randomized trial. Eur J Pediatr. 2011 Jan;170(1):59-63.

http://www.ncbi.nlm.nih.gov/pubmed/20689965

http://dx.doi.org/10.1007/s00431-010-1270-z

\begin{abstract}
The risk of upper respiratory infections (URIs) is increased in people who are under heavy physical stress, including recreational and competitive swimmers. Additional treatment options are needed, especially in the younger age group. The aim of this study was to determine whether $1 \mathrm{~g}$ /day vitamin $\mathrm{C}$ supplementation affects the rate, length, or severity of URIs in adolescent swimmers. We carried out a randomized, double-blind, placebo-controlled trial during three winter months, among 39 competitive young swimmers (mean age $13.8 \pm 1.6$ years) in Jerusalem, Israel. Vitamin $C$ had no effect on the incidence of URIs (rate ratio $=1.01 ; 95 \%$ confidence interval $(C I)=0.70-1.46$ ). The duration of respiratory infections was $22 \%$ shorter in vitamin $\mathrm{C}$ group, but the difference was not statistically significant. However, we found a significant interaction between vitamin $\mathrm{C}$ effect and sex, so that vitamin $\mathrm{C}$ shortened the duration of infections in male swimmers by $47 \%$ (95\% CI: $-80 \%$ to $-14 \%$ ), but had no effect on female swimmers (difference in duration: $+17 \%$; $95 \% \mathrm{CI}:-38 \%$ to $+71 \%$ ). The effect of vitamin $\mathrm{C}$ on the severity of URIs was also different between male and female swimmers, so that vitamin $\mathrm{C}$ was beneficial for males, but not for females. Our study indicates that vitamin $C$ does not affect the rate of respiratory infections in competitive swimmers. Nevertheless, we found that vitamin $\mathrm{C}$ decreased the duration and severity of respiratory infections in male swimmers, but not in females. This finding warrants further research.
\end{abstract}

Keywords: Athletes, Sport, Common cold, Antioxidants, Randomized controlled trial, Ascorbic acid 


\section{Introduction}

The risk of upper respiratory infections (URI) is increased in people who are under heavy physical stress, possibly because of changes in the immune function caused by heavy exertion [2]. Both recreational and competitive swimmers have an increased risk of URIs $[3,24]$, and therefore swimmers are a relevant population for studies examining the preventive and treatment methods against such infections.

In the general population, consisting mainly of sedentary people, vitamin $C$ has no effect on URI incidence [10]. However, in five randomized, double-blind trials with participants under short-term heavy physical stress, vitamin $C$ at doses of $0.25-1 \mathrm{~g} /$ day decreased the incidence of URI episodes on average by half $[5,10]$. These trials examined marathon runners [16-18], Canadian soldiers in a winter exercise [23] and Swiss schoolchildren in a 1-week skiing camp in the Swiss Alps [21, 22]. On the other hand, a 2-month randomized trial with US Marine recruits under recruit training did not find any reduction in URI incidence using $2 \mathrm{~g}$ /day of vitamin C [19]. It is possible that the effect of vitamin $\mathrm{C}$ on URI incidence is modified by the type of physical activity, so that it might be beneficial against short-term but not against long-term physical stress.

Modification of the antioxidant effect by the type of physical stress can be rationalized by the adaptation of the body to physical activity. Heavy physical activity causes oxidative stress in the body and endurance exercise training increases the activity of antioxidant enzymes such as superoxide dismutase and glutathione peroxidase [13, 20]. The body may adapt to regular physical activity by the increase in antioxidant enzyme levels. However, short-term and sporadic high-intensity activity might be more sensitive to vitamin C levels, since the antioxidant enzyme levels do not increase rapidly.

In regular vitamin $\mathrm{C}$ supplementation trials, usually administered every day, findings were a shortening of URI duration and alleviation of symptoms [10]. In children, doses of 1-2 g/day had shortened the duration of URI on average by $17 \%[7,10]$. No therapeutic vitamin $\mathrm{C}$ trials, meaning that administration starts after the onset of symptoms, have been carried out in children [7, 10]. During URI episodes, vitamin C levels in leukocytes and plasma are decreased $[4,12]$, and this consumption of vitamin $C$ during infections may be one explanation for the benefits of therapeutic vitamin $\mathrm{C}$ administration.

Although there is evidence indicating that vitamin C may affect the incidence of URI in some groups of physically stressed adults and children [4, 5, 16-18, 21, 23], the conditions under which vitamin $C$ supplementation may be beneficial are not well understood. The purpose of this trial was to test whether regular vitamin $C$ supplementation decreases the incidence or alleviates the symptoms of URI episodes in competitive adolescent swimmers. 


\section{Methods}

This was a randomized, double-blind, placebo-controlled trial conducted during the winter months in Jerusalem, Israel. The trial was approved by the Institutional Review Board of Clalit Health Services. Eligible participants were competitive adolescent swimmers from a local team ( $n=42$, mean age $13.8 \pm 1.6$ years, range $12-17$ years), of both sexes ( 24 males, 18 females), with a training volume of at least $15 \mathrm{~h} /$ week. Exclusion criteria were the presence of chronic health conditions and the use of prescription medications or dietary supplementations of any kind.

Participants received either vitamin C, $0.5 \mathrm{~g}$ twice daily ( $1 \mathrm{~g}$ /day), or placebo, administered for the three winter months from December to February. The vitamin (ascorbic acid) and placebo pills were prepared by a pharmaceutical company (Teva Pharmaceutical Industries Ltd., Netanya, Israel) and were identical in appearance. They were pre-packed in plastic bottles (identical number of vitamin $\mathrm{C}$ and placebo bottles) and, before their distribution to the swimmers, were numbered by a person unrelated to the study. Study participants were given a randomly selected plastic bottle, and its number was listed alongside the participant's name.

At baseline, following the signing of the informed consent forms, participants filled a questionnaire on demographic details and training volume, and were examined by a sports medicine specialist (NWC) to exclude the presence of any acute or chronic disease. All swimmers were asked to keep a daily record on URI symptoms chosen from a checklist, and training type and volume, throughout the 3-month study period. A URI event was defined as the appearance of rhinorrhea, nasal congestion, cough or sore throat, for at least two consecutive days, and at least three asymptomatic days after a previous event.

Furthermore, the participants were asked to grade the severity of each symptom, if present, each day. Perception of symptom severity on each sick day was self-assessed by a scoring of $1-4$, which corresponded with absent $(=1)$, mild $(=2)$, moderate $(=3)$, and severe $(=4)$. A cumulative score was calculated by summing the severity scores of the specific symptoms of each URI episode. Training volume was recorded each day during the study period, by having the participant register the duration of training in the pool or on land. Weekly meetings were conducted to collect the diaries and encourage adherence, count missing tablets and to provide a new bottle. Frequency, duration, and severity of URI were collected from the diaries.

\section{Statistical methods}

The outcome for URI incidence was the sum of the URI episodes for both intervention groups. The rate ratio and its 95\% confidence interval (95\% CI) were calculated by using the Poisson regression (SAS PROC GENMOD).

We used the $t$ test to calculate the estimate of effect and its 95\% CI for the duration and severity of vitamin $C$ and placebo groups (SAS PROC TTEST). The outcomes for the duration and severity of URI have two problems. First, several observations are obtained from the same participant, and thus there is the repeated measurement problem. Up to seven URI episodes were recorded per participant. If a person tends to have consistently short or long episodes, recording several episodes per person leads to misleading accuracy. Second, the distribution of the URI duration (and severity) is asymmetric and skewed to the right. For all 118 URI episodes, the median duration was 5.5 days, the minimum was 2 days and the maximum was 35 days (skewness 1.4). We dealt with these two problems as follows.

By using the linear regression (SAS PROC REG) we modeled the duration of the third, fourth, fifth, and the sixth URI episode as a function of all the preceding URI episodes. 
The duration of the third URI episode was not explained by the duration of the first and second URI episodes $\left(\mathrm{R}^{2}=0.05\right)$. The duration of the fourth URI episode was weakly explained by the three preceding episodes $\left(\mathrm{R}^{2}=0.54\right)$. However, the duration of the fifth and sixth URI episodes were strongly explained by the preceding episodes $\left(\mathrm{R}^{2}=0.83\right.$ and $\mathrm{R}^{2}=0.89$ ). Therefore, we included only the first four URI episodes for our analysis of the URI duration. This restriction led to the exclusion of 20 URI episodes (nine participants had five to seven URI episodes). Similarly, we restricted our analysis of the URI severity to the first four episodes.

We analyzed the interaction between vitamin C supplementation effect and four subgroup variables by using the unbalanced analysis of variance (the groups were not identical in size) (SAS PROC GLM). Because of the skewness of the URI duration and severity, in the interaction test we used the log-transformed duration and severity data. Age (median 15.6 years), duration of swimming (median $114 \mathrm{~h}$ per week) and distance of swimming (319 km per week) were dichotomized by the median; and the fourth variable in the subgroup analyses was sex (male/female).

Because the URI duration and severity data were skewed, we analyzed the data for the male swimmers also by using the non-parametric Wilcoxon text (SAS PROC NPAR1WAY) to calculate the $P$ value for the difference in the duration and severity of the first four URI episodes in the intervention groups.

Analyses were carried out by using SAS (release 8.02, SAS Institute, Cary, NC, USA). Two-tailed $P$ values were used.

Table 1 Clinical and training data of athletes in placebo and vitamin $\mathrm{C}$ groups

\begin{tabular}{|lll|}
\hline & Placebo & Vitamin C \\
\hline Number of participants $(n)$ & 18 & 21 \\
Age, years & $13.9 \pm 1.8$ & $13.7 \pm 1.5$ \\
Males $(n)$ & 10 & 12 \\
Swimming duration, h/week & $11 \pm 4$ & $11 \pm 4$ \\
Swimming distance, km/week & $34 \pm 13$ & $30 \pm 12$ \\
Fitness training, h/week & $2.3 \pm 1.9$ & $1.6 \pm 1.8$ \\
Other training, h/week & $2.3 \pm 2.0$ & $1.7 \pm 1.6$ \\
\hline
\end{tabular}

Values are $n$ or mean \pm SD, as appropriate

${ }^{a}$ e.g. Ball games, cycling, school activities

Table 2 The number of upper respiratory infections by treatment groups

\begin{tabular}{|llll|}
\hline & Placebo & Vitamin C & RR (95\% CI) \\
\hline Number of participants & 18 & 21 & \\
Number of URI episodes & 54 & 64 & $1.01(0.70,1.46)$ \\
\hline
\end{tabular}

RR rate ratio, URI upper respiratory infection 


\section{Results}

Of the 42 participants initially recruited to the trial, three dropped out, all from the placebo group. One dropped out immediately after the study began, and two withdrew from competitive swimming regardless of the study. They were not included in the analysis. The baseline data and training level for the two groups are shown in Table 1. The incidence of URIs in the placebo group was 12 episodes per person-year, and the mean duration of URI episodes in the placebo group was 9.0 days. The incidence of URI episodes was not different between the vitamin $C$ and placebo groups, but the wide confidence interval is also consistent with a reduction in URI incidence by 30\% (Table 2).

To minimize the problem of repeated measurement of the same participants, we restricted the analysis of vitamin C effect on URI duration and severity to the first four URI episodes of each participant (see "Methods" section). The duration of URI was 22\% shorter (95\% CI: $-52 \%$ to $+8 \%$ ) in the vitamin C group, but the confidence interval is consistent with no effect (Table 3). The severity of URI was lower in the vitamin $\mathrm{C}$ group, but also in this case, the confidence interval is consistent with no difference from placebo (Table 3).

Sex had a statistically significant interaction with the vitamin C effect on URI duration and severity (Table 3). Vitamin C decreased the duration and severity of URI in male swimmers, but had no effect on female swimmers. In the male swimmers, URI duration was decreased in the vitamin C group by $47 \%$ (95\% CI: $-80 \%$ to $-14 \%$; Table 3 ). In female swimmers, the duration of URI was non-significantly longer in the vitamin $\mathrm{C}$ groups ( $+17 \%$, $95 \%$ CI: $-38 \%$ to $+71 \%$; Table 3$)$.

Because of the skewness of the URI duration and severity data, we also tested the difference between the male swimmers from both groups by using the Wilcoxon test. There was a significant difference between the male intervention groups for the duration $(P=0.003)$ and severity $(P=0.03)$ of the first four URI episodes.

There was no statistically significant interaction between the effect of vitamin $\mathrm{C}$ on the duration and severity of URI and age, swimming duration or swimming distance (data not shown).

Table 3 The duration and severity of upper respiratory infections by treatment group

\begin{tabular}{|lllll|}
\hline & Placebo & Vitamin C & $\begin{array}{l}\text { Difference } \\
(95 \% \text { CI })\end{array}$ & $\begin{array}{l}\text { Test of } \\
\text { interaction }^{\mathrm{b}} P\end{array}$ \\
\hline Number of URI episodesa & 43 & 55 & & \\
Duration of URI episodes (days) (Mean \pm SD) & $8.9 \pm 7.8$ & $6.9 \pm 5.4$ & $-2.0(-4.6,+0.7)$ & \\
Males (21+30 episodes) & $10.4 \pm 7.1$ & $5.5 \pm 5.0$ & $-4.9(-8.4,-1.5)$ & 0.003 \\
Females (22+25 episodes) & $7.4 \pm 8.2$ & $8.6 \pm 5.5$ & $+1.2(-2.8,+5.3)$ & \\
Severity of URI episodes (Mean \pm SD) & $59 \pm 87$ & $43 \pm 45$ & $-16(-43,+11)$ & \\
$\quad$ Males (21+30 episodes) & $66 \pm 85$ & $26 \pm 30$ & $-40(-75,-6)$ & 0.003 \\
Females (22+25 episodes) & $52 \pm 89$ & $64 \pm 51$ & $+12(-30,+54)$ & \\
\hline
\end{tabular}

URI upper respiratory infection

${ }^{a}$ Data for this table is restricted to the first four URI episodes of the participants, see "Methods" section

${ }^{\mathrm{b}}$ The test of interaction was carried out with log transformed duration and severity 


\section{Discussion}

In this randomized, double-blind, placebo-controlled trial of $1 \mathrm{~g} /$ day vitamin $\mathrm{C}$ supplementation to adolescent competitive swimmers, we did not find any effect of vitamin $\mathrm{C}$ on the incidence of URI. However, we found a significant decrease in the duration and severity of URI episodes in male swimmers, but not in females.

Previous studies have suggested that the incidence of URIs is increased in physically active populations, including swimmers [3, 24]. In our cohort of young competitive swimmers, the incidence of URI was 12 episodes per person-year, which is substantially higher than the incidence in the general pediatric population, of three to six episodes per year in children and adolescents [14, 15].

In this trial, vitamin $\mathrm{C}$ supplementation did not decrease the incidence of URI, although the wide confidence interval does not rule out a possible effect of up to $30 \%$. Our trial was motivated by findings in short-term trials, lasting for 1 week at most, with physically stressed participants in which vitamin C decreased URI incidence [4, 5, 16-18, 21-23]. On the other hand, a 2-month trial with US Marine recruits did not find an effect of vitamin C on URI incidence [19]. It is possible that 2-3 months of regular training leads to an adaptation to physical stress, for example, through the increase of antioxidative enzyme levels [13, 20], whereas a short-term physical stress does not lead to such an adaptation. This hypothesis is supported by the findings on vitamin $\mathrm{E}$ and the incidence of pneumonia [8, 11]. Vitamin E reduced the risk of pneumonia by half in male smokers who exercised at leisure, but had no effect on participants who had physical stress because of a heavy job. Apparently, heavy jobs may lead to adaptation to physical stress, whereas sporadic leisure time exercise does not. This kind of adaptation might also explain the divergent findings between the effects of vitamin $C$ on URI incidence in people under short-term physical stress $[4,5,16-18,21-23]$ as opposed to those carrying out regular physical activity for at least several months [19].

In our study, the duration of URI episodes was $21 \%$ shorter in the vitamin C group, but the effect was not statistically significant. However, the effect was divergent between male and female swimmers so that vitamin $C$ halved the duration of URI episodes in males, but had no effect on females. Previous vitamin C trials have shown that regularly administered vitamin $\mathrm{C}$ shortens the duration of URI episodes that occur while on supplementation. In children, adding 1-2 g/day vitamin C shortened URI duration by $17 \%$ on average [10], which is close to the overall estimate for both sexes in this study.

To our knowledge, there are no previous reports indicating sex difference in the effect of vitamin $C$ on URI duration. Nevertheless, this is not the first study suggesting that sex may modify the effect of vitamin C on URI. Previously, sex-modification of vitamin C effect on URI incidence was found in trials that had been carried out in the UK [6]. Strongest evidence of sex-modification was reported in the study by Baird et al. [1, 9], conducted among British students. In these British studies, dietary vitamin C intake was low when the trials were carried out, which may explain the benefit seen. In addition, there was also evidence of lower vitamin C levels in males compared with females, which may explain the sex differences in the supplementation effect [6]. Thus, our findings and earlier ones indicate that, under some conditions, the effect of vitamin $\mathrm{C}$ supplementation on males and females may differ.

Our trial used a symptom-based definition of URI. Therefore, we do not know about the etiology of the symptoms. It is possible that some of the symptoms were caused by non-infectious irritation of swimmers' airways. However, from the practical point of view, this is not a major concern. If the subjective symptoms of male swimmers can be substantially reduced, this has a clinical benefit, irrespective of symptom etiology. Another limitation of our study is caused by the specific type of exercise - swimming. 
We do not know whether the benefit of vitamin $C$ is explained by the heavy regular training of the swimmers, or by the exposure to humidity, chlorine compounds, or other environmental substances. In the former case, the result could be extrapolated to other elite athletes; in the latter case, the observed effect would be restricted to swimmers.

Given that our main finding was the reduction in the URI duration in male adolescent swimmers, it is important to study the therapeutic effects of vitamin $C$ in young athletes from other disciplines. If therapeutic vitamin C use - meaning administration soon after the onset of URI symptoms - is as effective as regularly administered vitamin C, then the intervention would be cheaper and less demanding. On the other hand, the incidence of URI episodes was high in our male swimmers and the mean duration was 1 week. Thus, the male swimmers had respiratory symptoms over $25 \%$ of the study time. Therefore, it might also be reasonable to use regular supplementation, if the effect in male swimmers turns out to be repeatable.

\section{Conclusion}

In this randomized, double-blind, placebo-controlled trial of $1 \mathrm{~g} /$ day vitamin $\mathrm{C}$ supplementation, we found that vitamin $C$ halved the duration of URI episodes in male swimmers, and decreased their severity. No effect on duration or severity of colds was found in female swimmers, nor on the incidence of URI in both sexes. These findings suggest an important therapeutic option for URIs in young athletes, which warrants further research.

Acknowledgments The vitamin $\mathrm{C}$ and placebo pills for this study were kindly provided by Teva Pharmaceutical Industries Ltd., Israel.

Conflict of interest The authors declare that they have no conflict of interest nor any financial relations with the sponsoring organization. 


\section{References}

1. Baird IM, Hughes RE, Wilson HK, Davies JE, Howard AN (1979) The effects of ascorbic acid and flavonoids on the occurrence of symptoms normally associated with the common cold. Am J Clin Nutr 32:1686-1690 http://ajcn.nutrition.org/content/32/8/1686

2. Gleeson M (2007) Immune function in sport and exercise. J Appl Physiol 103:693-699 http://dx.doi.org/10.1152/japplphysiol.00008.2007

3. Gleeson M, Pyne DB, Austin JP, Lynn Francis J, Clancy RL, McDonald WA, Fricker PA (2002) Epstein-Barr virus reactivation and upper respiratory illness in elite swimmers. Med Sci Sports Exerc 34:411-417 http://dx.doi.org/10.1097/00005768-200203000-00005

4. Hemilä H (1992) Vitamin C and the common cold. Br J Nutr 67:3-16 http://dx.doi.org/10.1079/BJN19920004

5. Hemilä H (1996) Vitamin C and common cold incidence: a review of studies with subjects under heavy physical stress. Int J Sports Med 17:379-383 http://dx.doi.org/10.1055/s-2007-972864 http://hdl.handle.net/10250/7983 Links to references are added

6. Hemilä H (1997) Vitamin C intake and susceptibility to the common cold. Br J Nutr 77:59-72. Comments in: (1997) 78:857-866 http://dx.doi.org/10.1017/S0007114500002889 http://dx.doi.org/10.1079/BJN19970201 Comments

7. Hemilä H (1999) Vitamin C supplementation and common cold symptoms: factors affecting the magnitude of the benefit. Med Hypotheses 52:171-178 http://dx.doi.org/10.1054/mehy.1997.0639 http://hdl.handle.net/10250/8375 Links to references are added

8. Hemilä H (2006) Do vitamins C and E affect respiratory infections? [PhD Thesis]. Helsinki, Finland: University of Helsinki; pp 56-57, 66-67. Available at http://hdl.handle.net/10138/20335

9. Hemilä H (2008) Vitamin C and sex differences in respiratory tract infections.

Resp Med 102:625-626 http://dx.doi.org/10.1016/j.rmed.2007.12.011 http://hdl.handle.net/10250/8280 Links to references are added

10. Hemilä H, Chalker EB, Douglas RM (2010) Vitamin C for preventing and treating the common cold. Cochrane Database Syst Rev (3):CD000980 http://dx.doi.org/10.1002/14651858.CD000980.pub4 http://www.mv.helsinki.fi/home/hemila/CC/CC.htm http://www.mv.helsinki.fi/home/hemila/CC References to the review

11. Hemilä H, Kaprio J, Albanes D, Virtamo J (2006) Physical activity and pneumonia in male smokers administered vitamin $E$ and $\beta$-carotene. Int J Sports Med 27:336-341 http://dx.doi.org/10.1055/s-2005-865670 http://hdl.handle.net/10138/18749 Links to references are added

12. Hume R, Weyers E (1973) Changes in leucocyte ascorbic acid during the common cold. Scott Med J 18:3-7 http://www.mv.helsinki.fi/home/hemila/metabolism/Hume 1973 ch.pdf 
13. Ji LL (2008) Modulation of skeletal muscle antioxidant defense by exercise: role of redox signaling. Free Radical Biol Med 44:142-152 http://dx.doi.org/10.1016/j.freeradbiomed.2007.02.031

14. Lambert SB, Allen KM, Druce JD, Birch CJ, Mackay IM, Carlin JB, Carapetis JR, Sloots TP, Nissen MD, Nolan TM (2007) Community epidemiology of human metapneumovirus, human coronavirus NL63, and other respiratory viruses in healthy preschool-aged children using parent-collected specimens. Pediatrics 120:e929-e937 http://dx.doi.org/10.1542/peds.2006-3703

15. Monto AS, Ullman BM (1974) Acute respiratory illness in an American community. JAMA 227:164-169 http://dx.doi.org/10.1001/jama.1974.03230150016004

16. Moolla ME (1996) The effect of supplemental anti-oxidants on the incidence and severity of upper respiratory tract infections in ultra-marathon runners [MSc thesis]. University of Cape Town, South Africa http://www.mv.helsinki.fi/home/hemila/CC/Moolla 1996.pdf

17. Peters EM, Goetzsche JM, Grobbelaar B, Noakes TD (1993) Vitamin $\mathrm{C}$ supplementation reduces the incidence of postrace symptoms of upper-respiratory-tract infection in ultramarathon runners. Am J Clin Nutr 57:170-174 http://ajcn.nutrition.org/content/57/2/170

18. Peters EM, Goetzsche JM, Joseph LE, Noakes TD (1996) Vitamin C as effective as combinations of anti-oxidant nutrients in reducing symptoms of upper respiratory tract infection in ultramarathon runners. S Afr J Sports Med 11:23-27 http://www.sajsm.org.za/index.php/sajsm/article/download/430/384 (p.23) http://www.mv.helsinki.fi/home/hemila/CC/Peters 1996 ch.pdf

19. Pitt HA, Costrini AM (1979) Vitamin C prophylaxis in marine recruits. JAMA 241:908-911 http://dx.doi.org/10.1001/jama.1979.03290350028016

20. Powers SK, Jackson MJ (2008) Exercise-induced oxidative stress: cellular mechanisms and impact on muscle force production. Physiol Rev 88:1243-1276 http://dx.doi.org/10.1152/physrev.00031.2007

21. Ritzel G (1961) Kritische Beurteilung des Vitamins C als Prophylacticum und Therapeuticum der Erkältungskrankheiten [Critical analysis of the role of vitamin C in the treatment of the common cold]. Helv Med Acta 28: 63-68. Translation at: http://www.mv.helsinki.fi/home/hemila/T3.pdf

22. Ritzel G (1976) Ascorbic acid and the common cold [letter]. JAMA 235:1108 http://dx.doi.org/10.1001/jama.1976.03260370018017

23. Sabiston BH, Radomski MW (1974) Health Problems and Vitamin C in Canadian Northern Military Operations. DCIEM Report no. 74-R-1012. Defence and Civil Institute of Environmental Medicine; Downsview, Ontario, Canada. 10pp. Available at: http://www.mv.helsinki.fi/home/hemila/CC/Sabiston 1974 ch.pdf

24. Seyfried PL, Tobin RS, Brown NE, Ness PF (1985) A prospective study of swimming-related illness. I. Swimming-associated health risk.

Am J Public Health 75:1068-1070 http://dx.doi.org/10.2105/AJPH.75.9.1068 